\title{
Linear and nonlinear optical properties of some organoxenon derivatives
}

\author{
Aggelos Avramopoulos \\ Institute of Organic and Pharmaceutical Chemistry, National Hellenic Research Foundation, \\ 48 Vas. Constantinou Ave., Athens 11635, Greece \\ Luis Serrano-Andrés \\ Institute of Molecular Science, Universitat de València, Apartado 22085, ES-46071 Valencia, Spain \\ Jiabo Li \\ SciNet Technologies, San Diego, California 92127, USA
}

Heribert Reis and Manthos G. Papadopoulos ${ }^{\text {a) }}$

Institute of Organic and Pharmaceutical Chemistry, National Hellenic Research Foundation, 48 Vas. Constantinou Ave., Athens 11635, Greece

(Received 29 June 2007; accepted 25 September 2007; published online 4 December 2007)

\begin{abstract}
We employ a series of state-of-the-art computational techniques to study the effect of inserting one or more $\mathrm{Xe}$ atoms in $\mathrm{HC}_{2} \mathrm{H}$ and $\mathrm{HC}_{4} \mathrm{H}$, on the linear and nonlinear optical (L\&NLO) properties of the resulting compounds. It has been found that the inserted Xe has a great effect on the L\&NLO properties of the organoxenon derivatives. We analyze the bonding in $\mathrm{HXeC}_{2} \mathrm{H}$, and the change of the electronic structure, which is induced by inserting $\mathrm{Xe}$, in order to rationalize the observed extraordinary L\&NLO properties. The derivatives, which are of interest in this work, have been synthesized in a Xe matrix. Thus the effect of the local field (LF), due to the Xe environment, on the properties of $\mathrm{HXeC}_{2} \mathrm{H}$, has also been computed. It has been found that the LF effect on some properties is significant. The calculations have been performed by employing a hierarchy of basis sets and the techniques MP2 and $\operatorname{CCSD}(\mathrm{T})$ for taking into account correlation. For the interpretation of the results we have employed the complete active space valence bond and CASSCF/CASPT2 methods. () 2007 American Institute of Physics. [DOI: 10.1063/1.2800023]
\end{abstract}

\section{INTRODUCTION}

Pauling predicted that heavier noble gas atoms could participate in bond formation. ${ }^{1} \mathrm{He}$ explained this by invoking the reduced stability of their outer electrons, due to the strong screening of the inner electrons. Although predictions for stable noble gas derivatives can be found, since at least $1902,{ }^{2}$ the first $\mathrm{Xe}$ derivative, $\mathrm{XePtF}_{6}$, was not reported until 1962 by Bartlett, ${ }^{3}$ proving thus wrong the widely held opinion that the noble gases are inert. Bartlett's discovery was only the beginning for a large number of Xe derivatives, which have been reported since then. Christe ${ }^{4}$ considers that the recent burst of startling discoveries may signal the beginning of a renaissance in the noble gas chemistry.

Among the many important recent developments in the Xe chemistry, we note the fluorinated Xe derivatives [e.g., $\mathrm{XeF}_{2} \mathrm{XeF}_{4}$ (Ref. 5)], their cations (e.g., $[\mathrm{XeF}]^{+}$), the organoxenonium salts ${ }^{4,6}$ as well as the preparation and characterization of hydrides $\mathrm{HXe} Y$, where $Y$ denotes an electronegative group. ${ }^{7}$

The first stable derivative, with a $\mathrm{Xe}-\mathrm{C}$ bond, has been reported by Frohn and Jakobs in $1989 .{ }^{8}$ Since then many compounds involving the bond $\mathrm{Xe}-\mathrm{C}$ have been synthesized. ${ }^{9}$ We note that Fankowski et al. ${ }^{10}$ prepared $\mathrm{XeC}_{2}$, the structure of which is bent and it is characterized by substantial charge separation.

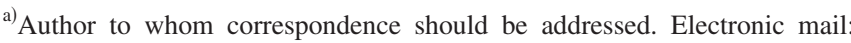
mpapad@eie.gr.
}

The first prediction for a fluorine-free alkynylxenon compound was reported by Lundell et al., ${ }^{6}$ who discussed the stability and reported the spectroscopic properties of $\mathrm{HXeC}_{2} \mathrm{H}, \mathrm{HXeC}_{2} \mathrm{XeH}$, and some other organoxenon derivatives. Khriachtchev et al. ${ }^{9}$ synthesized and identified $\mathrm{HXeC}_{2} \mathrm{H}$ and $\mathrm{HXeC}_{2} \mathrm{XeH}$, while experimental evidence for the formation of $\mathrm{HXeC}_{2} \mathrm{H}$ has also been reported simultaneously by Feldman et al. ${ }^{11}$ These derivatives do not contain fluorine, which distinguishes them from previous organoxenon compounds. It is noted that since the electron affinity of the $\mathrm{C}_{2 n} \mathrm{H}$ radicals increases with $n$, then the stability of $\mathrm{HXeC}_{2 n} \mathrm{H}$ should enhance with increasing $n .{ }^{11}$ The strong electronegative character of $\mathrm{C}_{2}$ has been pointed out by Maier and Lautz. ${ }^{12}$

Insertion compounds of $\mathrm{Xe}$ into $\mathrm{HC}_{n} \mathrm{H}$ are prepared by dissociation of the appropriate precursor in solid Xe by UV light or fast electrons. This process is followed by annealing. ${ }^{9,11}$ For example, Tanskanen et al. ${ }^{13}$ reported the synthesis of $\mathrm{HXeC}_{4} \mathrm{H}$, which involves UV photolysis of $\mathrm{C}_{4} \mathrm{H}_{2}$ in a Xe matrix and annealing. Global diffusion of $\mathrm{H}$ atoms in solid $\mathrm{Xe}$ at $\sim 40 \mathrm{~K}$ leads to the reaction $\mathrm{H}+\mathrm{Xe}$ $+\mathrm{C}_{4} \mathrm{H}$ and the production of $\mathrm{HXeC}_{4} \mathrm{H}$. The considered rare gas molecules easily decompose upon irradiation by light.

In the present work we report the linear and nonlinear optical (L\&NLO) properties of $\mathrm{HXeC}_{2} \mathrm{H}, \mathrm{HXeC}_{2} \mathrm{XeH}$, and three of the Xe derivatives of $\mathrm{HC}_{4} \mathrm{H}$. We consider the following questions: (i) how the inserted $\mathrm{Xe}$ affects the L\&NLO properties of $\mathrm{HXeC}_{2} \mathrm{H}$ and (ii) how the position of 
$\mathrm{Xe}$ in $\mathrm{HC}_{4} \mathrm{H}$ as well as the number of $\mathrm{Xe}$ atoms affect the L\&NLO properties of the organoxenon derivative. Electronic, and to a smaller extent vibrational, contributions to the L\&NLO properties are computed. As the Xe derivatives have been synthesized in a Xe matrix, we also calculated the effect of the environment, which consists of Xe atoms, on the studied L\&NLO properties.

Insertion of $\mathrm{Xe}$ in $\mathrm{HC}_{2} \mathrm{H}$ or $\mathrm{HC}_{4} \mathrm{H}$ induces a considerable change in the electronic structure. We have thus discussed the bonding in $\mathrm{HXeC}_{2} \mathrm{H}$ and how the changes in the electronic structure affect the L\&NLO properties.

The L\&NLO properties are of great current interest, because they allow to advance our understanding of the electronic and vibrational structure of the molecules. In addition, they are key parameters for the design of materials with many applications (e.g., fiber optic communication, all optical switching).

This work is organized as follows. In the second section, we present the computational methods, which have been employed for the calculation of the L\&NLO properties of the considered derivatives; in the third section, the L\&NLO properties are presented as well as their interpretation, and finally the fourth section involves the concluding remarks.

\section{COMPUTATIONAL METHODS}

The geometries, harmonic frequencies, and (hyper)polarizabilities of a series of organoxenon derivatives are presented. A hierarchy of computational techniques has been employed including HF, MP2, and $\operatorname{CCSD}(\mathrm{T})$. The coupled cluster approach, which involves the iterative calculation of single and double excitation amplitudes as well as a perturbative treatment of triple excitations, has been selected, because it provides a satisfactory estimate of the correlation contribution, ${ }^{14}$ while MP2 is one of the most frequently used techniques for the calculation of the above contribution. We have performed CASSCF calculations for the ground state of the studied molecules, at the same level as those later described for $\mathrm{C}_{2} \mathrm{H}_{2}$ and $\mathrm{HXeC}_{2} \mathrm{H}$, and in all cases one single electronic configuration dominated the wave function, at least by $87 \%$. The computations have been performed by employing the aug-cc-pVnZ, where $n=2-5 .{ }^{15}$ This systematically built series of basis sets allows the extrapolation to the "complete" basis set limit. By such a procedure one may estimate the error associated with a given approximate wave function. ${ }^{16}$ We have also employed the HyPol basis set, developed by Sadlej et al.,${ }^{17}$ which is known to give reasonably accurate (hyper)polarizabilities.

For Xe, a small core (28 electrons), energy consistent, relativistic pseudopotential (PP) has been used. ${ }^{18}$ The $4 s p d$ outer-core shell is treated explicitly together with the $5 \mathrm{sp}$ valence orbitals. The usefulness and reliability of the pseudopotentials and, in particular, the large-core ones for the calculation of (hyper)plarizabilities have been discussed by various authors. ${ }^{19-21}$ The relativistic correction to the L\&NLO properties has been estimated by employing the Douglas-Kroll approximation, ${ }^{22}$ in connection with the HyPol basis, ${ }^{17}$ which has been specifically developed for relativistic calculations.
The properties of the considered derivatives have been computed by employing geometries optimized at the HF or MP2 levels. In addition, for two derivatives geometry data have been taken from the literature. The method which has been used for each molecule is specified. The geometry optimizations, which have been performed in this work, employed the aug-cc-pVDZ basis sets for H, C, and Xe. For the latter the basis set has been developed in connection with the employed pseudopotential. ${ }^{18}$

The vibrational contributions to the polarizability and first hyperpolarizability of $\mathrm{H}-\mathrm{XeC}_{2} \mathrm{H}$ have been also computed. At static fields $(\omega=0)$ the pure vibrational $(\mathrm{pv})$ term may have a significant contribution. Bishop and Kirtman ${ }^{23-26}$ developed a perturbation theory approach for the calculation of $\alpha_{z z}^{p v}$ and $\beta_{z z z}^{p v}$. In the present work we use a double harmonic approximation for the evaluation of these properties:

$$
\begin{aligned}
& a_{i i}^{\mathrm{pv}}=\left[\mu^{2}\right]_{i i}^{(0,0)}=\sum_{a} \frac{\left(\partial \mu_{i}^{e} / \partial Q_{\alpha}\right)_{0}\left(\partial \mu_{i}^{e} / \partial Q_{\alpha}\right)_{0}}{\omega_{a}^{2}}, \\
& \beta_{i i i}^{\mathrm{pv}}=[\mu \alpha]_{i i i}^{(0,0)}=3 \sum_{a} \frac{\left(\partial \mu_{i}^{e} / \partial Q_{\alpha}\right)_{0}\left(\partial \alpha_{i i}^{e} / \partial Q_{\alpha}\right)_{0}}{\omega_{a}^{2}},
\end{aligned}
$$

where $i=x, y, z$ and $\omega_{\alpha}$ are the harmonic frequencies. The required dipole moment and polarizability derivatives have been computed at the HF and MP2 levels of theory by employing the aug-cc-pVDZ basis set.

Local field expression in dipolar approximation. The Xe derivatives, which are studied in this work, are produced in a Xe matrix. The L\&NLO properties computed and reported here refer to isolated molecules. Thus it would be useful and interesting to find out the effect of the environment of the surrounding $\mathrm{Xe}$ atoms on the $\mathrm{L} \& \mathrm{NLO}$ properties of $\mathrm{HXeC}_{2} \mathrm{H}$, which will be considered as a model compound. We shall first determine the local field ${ }^{27}$ by employing Eq. (3):

$$
F_{k^{\prime} \alpha}=\left(\varepsilon_{0} V_{\text {cell }}\right)^{-1} \sum_{k^{\prime} \neq k}^{N} L_{k k^{\prime}, \alpha \beta}^{(11)}\left[\mu_{k^{\prime} \beta}+\alpha_{k^{\prime}, \beta \gamma} F_{k^{\prime} \gamma}\right],
$$

where $N$ is the number of the molecules in the cell, $\alpha, \beta, \gamma$ are Cartesian components, $F_{k^{\prime} \alpha}$ denotes the permanent local field on molecule $k^{\prime}$ due to the surrounding molecules at sites $k, V_{\text {cell }}$ is the volume of the cell, $\varepsilon_{0}$ the permittivity of vacuum, $\mu_{k^{\prime} \beta}$ and $\alpha_{k^{\prime} \alpha \beta}$ are the dipole moment and polarizability components of the free molecule $k^{\prime}$, respectively, and $L^{(11)}$ is the Lorentz-factor tensor computed in conducting boundary conditions. The local field (LF) is found by an iterative procedure. The approximated LF, given by Eq. (3), is due to a specified number of $\mathrm{Xe}$ atoms. These define the environment of $\mathrm{HXeC}_{2} \mathrm{H}$. Then in the presence of the determined LF, we shall compute the L\&NLO properties of $\mathrm{HXeC}_{2} \mathrm{H}$. In that way, we shall be able to estimate the effect of the local field.

The bonding of the considered derivatives has been studied by employing the complete active space valence bond (CASVB) theory ${ }^{28}$ and the vB2000 software. ${ }^{29}$ The CASSCF/ CASPT2 (Ref. 30) method has also been used in order to comment on the changes in the electronic structure of $\mathrm{HC}_{2} \mathrm{H}$, 
TABLE I. The equilibrium structure of $\mathrm{H}-\mathrm{Xe}-\mathrm{C} \equiv \mathrm{C}-\mathrm{H}$ (in $\AA$ ) and the harmonic frequencies $\left(\right.$ in $^{\mathrm{c}} \mathrm{cm}^{-1}$ ) of $\mathrm{H}-\mathrm{Xe}-\mathrm{C} \equiv \mathrm{C}-\mathrm{H}$.

\begin{tabular}{|c|c|c|c|c|c|c|c|c|c|c|c|}
\hline Method & $R(\mathrm{C} \equiv \mathrm{C})$ & $R(\mathrm{C}-\mathrm{H})$ & $R(\mathrm{Xe}-\mathrm{C})$ & $R(\mathrm{H}-\mathrm{Xe})$ & $\omega(\mathrm{C}-\mathrm{H})$ & $\omega(\mathrm{C} \equiv \mathrm{C})$ & $\omega(\mathrm{Xe}-\mathrm{H})$ & Bend $^{\mathrm{a}}$ & Bend $^{\mathrm{a}}$ & $\psi(\mathrm{Xe}-\mathrm{C})$ & $\omega(\mathrm{H}-\mathrm{Xe}-\mathrm{C})^{\mathrm{a}}$ \\
\hline MP2/aug-cc-pVDZ & 1.249 & 1.078 & 2.350 & 1.750 & 3444.3 & 1931.1 & 1681.3 & 676.8 & 612.6 & 313.4 & 153.1 \\
\hline MP2/aug-cc-pVTZ ${ }^{c}$ & 1.230 & 1.064 & 2.329 & 1.734 & & & & & & & \\
\hline MP2/LJ18/6-311++G(2d,2p) ${ }^{\mathrm{d}}$ & 1.225 & 1.062 & 2.322 & 1.750 & 3462.3 & 1970.4 & 1735.9 & 687.8 & 640.6 & 327.2 & 131.4 \\
\hline $\operatorname{CCSD}(\mathrm{T}) / \mathrm{LJ} 18 / 6-311++\mathrm{G}(2 d, 2 p)^{\mathrm{e}}$ & 1.223 & 1.065 & 2.351 & 1.767 & 3419.9 & 2000.4 & 1620.8 & 657.6 & 614.2 & 313.2 & 131.6 \\
\hline B3LYP/LANL2DZ ${ }^{\mathrm{f}}$ & 1.237 & 1.069 & 2.405 & 2.320 & & & & & & & \\
\hline Experiment $^{\mathrm{g}}$ & & & & & 3273 & 1748 & 1486 & 626 & & & \\
\hline
\end{tabular}

"Doubly degenerate.

${ }^{\mathrm{b}}$ The basis sets for $\mathrm{H}$ and $\mathrm{C}$ have been taken from Ref. 15 and for Xe from Ref. 18. Xe is treated with a small core relativistic pseudopotential.

${ }^{\mathrm{c}}$ The employed basis sets, as well as the pseudopotential used for Xe are described in footnote $\mathrm{b}$.

${ }^{\mathrm{d}}$ Reference 6. A pseudopotential has been employed for Xe with core $(Q)$ involving 36 electrons. [Ref. 70(a)].

${ }^{\mathrm{e}}$ Reference 6. Information for the employed pseudopotential for Xe is given in footnote $\mathrm{d}$.

${ }^{\mathrm{f}}$ Reference 35. $Q(\mathrm{Xe})=46$ electrons [Ref. 70(b)].

${ }^{\mathrm{g}}$ References 9 and 11.

which are induced by the insertion of Xe, and which are essential for the analysis of the L\&NLO properties of the Xe derivatives. For the computations the following programs have been used: GAUSSIAN $98,{ }^{31}$ DALTON,${ }^{32}$ MOLCAS,${ }^{33}$ and VB2000. ${ }^{29}$ The reported L\&NLO properties are given in a.u. Conversion factors to Systéme International (SI) are given in Ref. 34.

\section{RESULTS AND DISCUSSION}

In this section we present (i) the equilibrium structure and the harmonic frequencies of $\mathrm{HXeC}_{2} \mathrm{H}$; (ii) the chemical bonding in $\mathrm{HXeC}_{2} \mathrm{H}$; (iii) the charge transfer, which takes place in the considered Xe derivatives, as well as between $\mathrm{HXeC}_{2} \mathrm{H}$ and the Xe environment; (iv) the L\&NLO properties (electronic contributions) of the organoxenon compounds together with the factors which affect them (e.g., basis set, correlation, relativistic correction, etc.); (v) the vibrational contributions to L\&NLO properties; and (vi) the effect of the local field, which is due to the Xe environment, on the properties of interest. Particular care has been taken for the analysis and interpretation of the presented results.

\section{A. Structure and harmonic frequencies}

The structure of the molecules of interest has been either optimized in the present work or taken from the literature (Table I). All the considered molecules are linear except of $\mathrm{HXeC}_{2} \mathrm{XeC}_{2} \mathrm{XeH}$, which has a slightly nonlinear structure. We have found that the $\mathrm{C}-\mathrm{C}-\mathrm{Xe}$ angle is bent by $2^{\circ}$, while Lundell et al. ${ }^{6}$ found an angle of $\sim 4^{\circ}$. The slightly bent structure of this molecule explains the small computed $\mu_{z}$ and $\beta_{z z z}$.

The effect of the basis set on the bond lengths of $\mathrm{HXeC}_{2} \mathrm{H}$ has also been studied, by employing MP2/aug-cc$\mathrm{pV} n \mathrm{Z}$, where $n=2,3$. It is observed that both basis sets give similar results, which are in satisfactory agreement with those reported by Lundell et al. ${ }^{6}$ and Brown et al. ${ }^{35}$ Thus for the geometry optimization of the larger molecules we shall employ the aug-cc-pVDZ method. In Fig. 1 we present the optimized structure of $\mathrm{HXeC}_{2} \mathrm{XeH}$ (MP2) and $\mathrm{HXeC}_{2} \mathrm{XeC}_{2} \mathrm{XeH}(\mathrm{HF})$. The methods of optimization are shown in parentheses.

The harmonic frequencies of $\mathrm{HXeC}_{2} \mathrm{H}$ have also been reported (Table I). We computed them at the MP2/aug-ccpVDZ level. Our values differ from the experimental ones by $5.0 \%-11.6 \%$. This discrepancy is due to (a) neglect of anharmonicity effects and (b) the experimental frequencies refer to $\mathrm{HXeC}_{2} \mathrm{H}$, trapped in solid Xe. The Xe matrix effects are not taken into account by our values. Runeberg et al. ${ }^{36(\mathrm{a})} \mathrm{em}-$ ploying HArF as a model have shown that when the anharmonicities and the matrix effects are taken into account the computed values (LMP2/AVDZ) approach satisfactorily the experimental data. The harmonic frequencies are essential for the computation of the vibrational properties, which we shall discuss.

\section{B. Chemical bonding}

We selected $\mathrm{HXeC}_{2} \mathrm{H}$, as an example of the considered derivatives, in order to discuss the nature of chemical bonding in the considered systems. For this compound, CASVB calculations were performed, using VB2000, ${ }^{29}$ an $a b$ initio valence bond program based on an algebrant algorithm and group function theory. ${ }^{28}$

The CASVB method is equivalent to CASSCF, with the following advantage. Since the VB orbitals can be nonorthogonal and the CASVB wave function is invariant under an arbitrary linear transformation of the basis of the CAS space, the maximum localization of VB orbitals can be performed without losing any accuracy. By default, the VB2000 program maximizes orbital localization for the CASVB wave

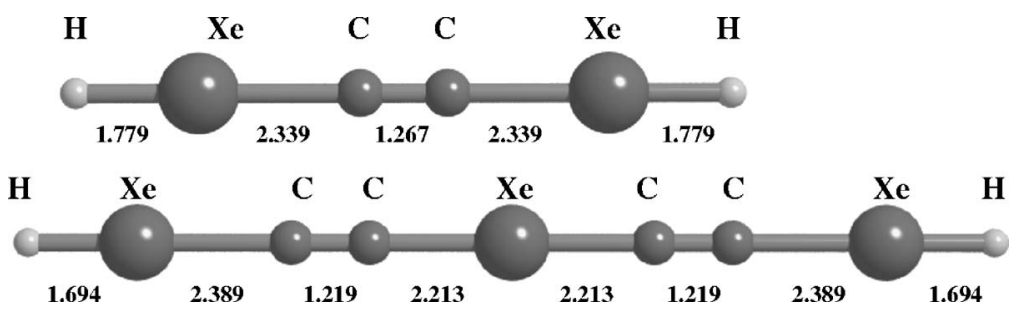

FIG. 1. The structure of $\mathrm{HXeC}_{2} \mathrm{XeH}$ and $\mathrm{HXeC}_{2} \mathrm{XeC}_{2} \mathrm{XeH}$. The bond lengths are in $\AA$. 
TABLE II. The resonance structures of $\mathrm{HXeC}_{2} \mathrm{H}$ and the corresponding weights, energies (a.u.), dipole moments (a.u.), and atomic charges.

\begin{tabular}{|c|c|c|c|c|c|c|c|c|}
\hline \multirow[b]{2}{*}{ Structures } & \multirow[b]{2}{*}{ Weight $(\%)^{\mathrm{a}}$} & \multirow[b]{2}{*}{ Energy } & \multirow[b]{2}{*}{ Dipole moment } & \multicolumn{5}{|c|}{ Atomic charges ${ }^{\mathrm{b}}$} \\
\hline & & & & $\mathrm{H}$ & $\mathrm{Xe}$ & $\mathrm{C}$ & $\mathrm{C}$ & $\mathrm{H}$ \\
\hline $\mathrm{H}-\mathrm{Xe}^{+} \mathrm{C}^{-} \mathrm{CH}(\mathrm{I})$ & 44 & -7276.9008 & -2.989 & 0.08 & 0.73 & -0.66 & -0.29 & 0.13 \\
\hline $\mathrm{H} \cdot \mathrm{Xe} \cdot \mathrm{CCH}(\mathrm{II})$ & 26 & -7276.8174 & 0.301 & 0.03 & 0.00 & 0.07 & -0.24 & 0.14 \\
\hline $\mathrm{H}^{-} \mathrm{Xe}^{+}-\mathrm{CCH}$ (III) & 14 & -7276.6906 & 3.194 & -0.74 & 0.71 & 0.12 & -0.23 & 0.14 \\
\hline $\mathrm{H}^{-} \mathrm{Xe}^{2+} \mathrm{C}^{-} \mathrm{CH}$ (IV) & 11 & -7276.6305 & -0.088 & -0.70 & 1.47 & -0.61 & -0.28 & 0.13 \\
\hline $\mathrm{H}^{+} \mathrm{XeC}^{-} \mathrm{CH}(\mathrm{V})$ & 5 & -7276.5544 & -6.055 & 0.85 & 0.04 & -0.73 & -0.29 & 0.13 \\
\hline $\operatorname{CASVB}(6,4)$ & & -7277.0212 & -1.149 & -0.07 & 0.54 & -0.34 & -0.26 & 0.14 \\
\hline
\end{tabular}

${ }^{\mathrm{a}}$ The weights of resonance structures are computed according to Coulson-Chirgwin formula. (Ref. 36).

${ }^{\mathrm{b}}$ The Löwdin population analysis was used for computing atomic charges.

function. The localization of the VB orbitals makes the interpretation of the CASVB wave function, in terms of resonance structures, particularly attractive.

The CASVB $(6,4)$ space (that is, six electrons distributed in four orbitals) was used for the description of the chargeshifting bonding in $\mathrm{HXeC}_{2} \mathrm{H}$. The $3-21 \mathrm{G}^{*}$ basis set was employed, which is considered adequate for our analysis. We recall that although in our computations $\mathrm{Xe}$ is treated by employing a PP, this has not yet been implemented in VB2000; thus all electron computations have been performed with this software. The above defined four orbitals are one $s$ and one $p$ orbital for $\mathrm{Xe}$, one $s$ orbital for $\mathrm{H}$, and one $s p$ (hybrid) orbital for carbon next to Xe. Hydrogen and carbon provide one electron each and Xe provides four. The $p$ orbital for Xe is pointing to its two neighbors. The relativistic correction has not been taken into account in the CASVB computations. However, the relativistic effect on the bonding of $\mathrm{HXeC}_{2} \mathrm{H}$ is expected to be quite small, since only the valence $s$ and $p$ orbitals of $\mathrm{Xe}$ are involved in the bonding.

There are ten VB structures in the CASVB $(6,4)$ wave function. However, only five resonance structures have significant contribution to the CASVB wave function (Table II). The other five resonance structures, which have been neglected in the present analysis, have extremely small contribution; the sum of their weights is less than $1 \%$. The weights have been computed according to the Coulson-Chirgwin formula (or sometimes called Mulliken-type weights). ${ }^{36(\mathrm{~b})}$

Table II shows that structure (I) has the largest weight and the positive charge is mainly localized on Xe, as it is in structures (III) and (IV). However, in structure (V) it is mainly localized on $\mathrm{H}$ (bonded with $\mathrm{Xe}$ ). In all five significant resonance structures of $\mathrm{HXeC}_{2} \mathrm{H}$, the $5 s$ orbital of $\mathrm{Xe}$ is not actively involved in the bonding (this orbital is always doubly occupied), but the $5 p_{z}(\mathrm{Xe})$ orbital is involved in bonding.

It has been found that $\mathrm{HXeC}_{2} \mathrm{H}$ has a very large covalent-ionic resonance energy (Table II).The energy difference between that of structure (I) and the CASVB wave function is $75 \mathrm{kcal} / \mathrm{mol}$. The bonds between $\mathrm{Xe}$ and its neighbor atoms ( $\mathrm{H}$ and $\mathrm{C}$ ) are not ordinary covalent or ionic bonds. The bonding energy comes from the very strong resonance energy between the charge-shift (ionic) structures and neutral structure (II). This is typical for lone-pair rich molecules (e.g., $\mathrm{F}_{2}$ ), as Hiberty et al. ${ }^{37}$ recently have reported.

The structure weights show why the molecule has a di- pole moment pointing from right to left $\left(\mathrm{HXeC}_{2} \mathrm{H}\right)$. The major resonance structure (I) has a positive charge on $\mathrm{Xe}$, and a negative charge on carbon with which it is bonded; therefore the dipole moment is pointing from $\mathrm{C}$ to $\mathrm{Xe}$.

\section{Charge transfer}

Two processes of charge transfer will be considered for the analysis of the reported results. The first is related with the charge transferred from $\mathrm{Xe}$ to the rest of the molecule (e.g., in $\mathrm{HXeC}_{2} \mathrm{H}$ ). As we have shown in the previous work on the NLO properties of $\mathrm{HArF}^{38}{ }^{38}$ the involved charge transfer is instrumental for the analysis of the properties of interest. The natural bond orbital (NBO) charge distribution of the considered Xe derivatives is reported in Table III. The discussion, which relies on the NBO charges, is complementary to the analysis of the VB resonance structures, which was given in the previous paragraphs. The NBO charges have been computed by employing the HF and MP2 techniques. There is no substantial difference between the results computed with the above methods.

We observe that Xe of $\mathrm{HXeC}_{2} \mathrm{H}$, and to a less extent $\mathrm{H}$, bonded to $\mathrm{C}_{2}$, carry a positive charge. The rest of the molecule has a negative charge. Similar charges have been computed for $\mathrm{HXeC}_{4} \mathrm{H}$. It is interesting to note that the NBO analysis for $\mathrm{HXeC}_{2} \mathrm{H}$, given in Table III, and the Löwdin population analysis presented in Table II, are in qualitative agreement. The two $\mathrm{Xe}$ atoms of $\mathrm{HXeC}_{2} \mathrm{XeH}$ represent the positively charged part of the molecule. All the other atoms have a negative charge. The $\mathrm{Xe}$ atom of $\mathrm{HC}_{2} \mathrm{XeC}_{2} \mathrm{H}$ has a remarkably larger positive charge than that of $\mathrm{HXeC}_{4} \mathrm{H}$ (Table III).

The $\mathrm{Xe}$ atom in the middle of $\mathrm{HXeC}_{2} \mathrm{XeC}_{2} \mathrm{XeH}$ has a larger positive charge than the Xe atoms, which approach the ends of the molecule (Table III). This observation is in agreement with the result found in the pair $\mathrm{HXeC}_{4} \mathrm{H} / \mathrm{HC}_{2} \mathrm{XeC}_{2} \mathrm{H}$. It has been found that the $\mathrm{H}$ atoms in $\mathrm{HC}_{2} \mathrm{XeC}_{2} \mathrm{H}$ have a positive charge, while in $\mathrm{HXeC}_{2} \mathrm{XeC}_{2} \mathrm{XeH}$, the $\mathrm{H}$ atoms have a small negative charge.

Comparison of the charge of $\mathrm{Xe}$ in the pair $\mathrm{HXeC}_{2} \mathrm{H} / \mathrm{HXeC}_{4} \mathrm{H}$ shows the negligible effect of the chain length on the charge of Xe (Table III). The pair $\mathrm{HXeC}_{2} \mathrm{H} / \mathrm{HXeC}_{2} \mathrm{XeH}$ allows to comment on the effect of the increasing number of $\mathrm{Xe}$ atoms on their charge. In the considered example the above effect is small. 
TABLE III. Natural bond orbital charge distribution of some Xe derivatives.

\begin{tabular}{|c|c|c|c|c|c|c|c|c|c|c|c|c|c|c|c|}
\hline \multicolumn{5}{|c|}{$\mathrm{HXeC}_{2} \mathrm{H}$} & \multicolumn{3}{|c|}{$\mathrm{HXeC}_{2} \mathrm{XeH}$} & \multicolumn{3}{|c|}{$\mathrm{HXeC}_{4} \mathrm{H}$} & \multicolumn{3}{|c|}{$\mathrm{HC}_{2} \mathrm{XeC}_{2} \mathrm{H}$} & \multicolumn{2}{|c|}{$\mathrm{HXeC}_{2} \mathrm{XeC}_{2} \mathrm{XeH}$} \\
\hline Atom & $\mathrm{HF}^{\mathrm{a}}$ & $\mathrm{MP} 2^{\mathrm{b}}$ & $\begin{array}{l}\text { Lundell } \\
\text { et al. }\end{array}$ & $\begin{array}{l}\text { Brown } \\
\text { et al. }\end{array}$ & Atom & $\mathrm{HF}$ & MP2 & Atom & $\mathrm{HF}$ & MP2 & Atom & $\mathrm{HF}$ & MP2 & Atom & HF \\
\hline $\mathrm{H}$ & -0.10 & -0.11 & -0.17 & -0.10 & $\mathrm{H}$ & -0.15 & -0.14 & $\mathrm{H}$ & -0.09 & -0.10 & $\mathrm{H}$ & 0.23 & 0.22 & $\mathrm{H}$ & -0.09 \\
\hline $\mathrm{Xe}$ & 0.79 & 0.70 & 0.77 & 0.54 & $\mathrm{Xe}$ & 0.78 & 0.68 & $\mathrm{Xe}$ & 0.79 & 0.71 & $\mathrm{C}$ & -0.25 & -0.25 & $\mathrm{Xe}$ & 0.78 \\
\hline $\mathrm{C}$ & -0.57 & -0.51 & -0.49 & -0.32 & $\mathrm{C}$ & -0.63 & -0.54 & $\mathrm{C}$ & -0.46 & -0.41 & $\mathrm{C}$ & -0.49 & -0.43 & $\mathrm{C}$ & -0.59 \\
\hline $\mathrm{C}$ & -0.34 & -0.30 & -0.31 & -0.38 & $\mathrm{C}$ & -0.63 & -0.54 & $\mathrm{C}$ & -0.20 & -0.16 & $\mathrm{Xe}$ & 1.02 & 0.91 & $\mathrm{C}$ & -0.59 \\
\hline \multirow[t]{5}{*}{$\mathrm{H}$} & 0.23 & 0.22 & 0.20 & 0.26 & $\mathrm{Xe}$ & 0.78 & 0.68 & $\mathrm{C}$ & -0.07 & -0.08 & $\mathrm{C}$ & -0.49 & -0.43 & $\mathrm{Xe}$ & 0.98 \\
\hline & & & & & $\mathrm{H}$ & -0.15 & -0.14 & $\mathrm{C}$ & -0.20 & -0.18 & $\mathrm{C}$ & -0.25 & -0.25 & $\mathrm{C}$ & -0.59 \\
\hline & & & & & & & & $\mathrm{H}$ & 0.24 & 0.23 & $\mathrm{H}$ & 0.23 & 0.23 & $\mathrm{C}$ & -0.59 \\
\hline & & & & & & & & & & & & & & $\mathrm{Xe}$ & 0.78 \\
\hline & & & & & & & & & & & & & & $\mathrm{H}$ & -0.09 \\
\hline
\end{tabular}

${ }^{\mathrm{a} M e t h o d: ~ H F / a u g-c c-p v D Z . ~ X e: ~ S C ~ p s e u d o p o t e n t i a l ; ~} Q=28$ (Ref. 18).

${ }^{\mathrm{b}}$ Method: MP2/aug-cc-pvDZ; Xe: small core (SC) pseudopotential; $Q=28$ (Ref. 18). Footnote c of Table I.

${ }^{c}$ Method: MP2/LJ18/6-311++G(2d,2p) (footnote d, Table I).

${ }^{\mathrm{d}}$ Method: B3LYP/LANL2DZ (footnote f, Table I).

It is understood that the considered Xe derivatives are produced in a Xe matrix. Thus it would be useful to find out if some significant charge transfer takes place in the system $\{\mathrm{Xe}$ matrix $\} /\{\mathrm{Xe}$ derivative $\}$. Two models have been adopted for the discussion of this question. The first involves six $\mathrm{Xe}$ atoms octahedrally placed around $\mathrm{HXeC}_{2} \mathrm{H}$ (Fig. 2). The distances $A_{1} A_{2}$ (7.56 a.u.) and $A_{2} A_{3}$ (9.45 a.u.) were optimized

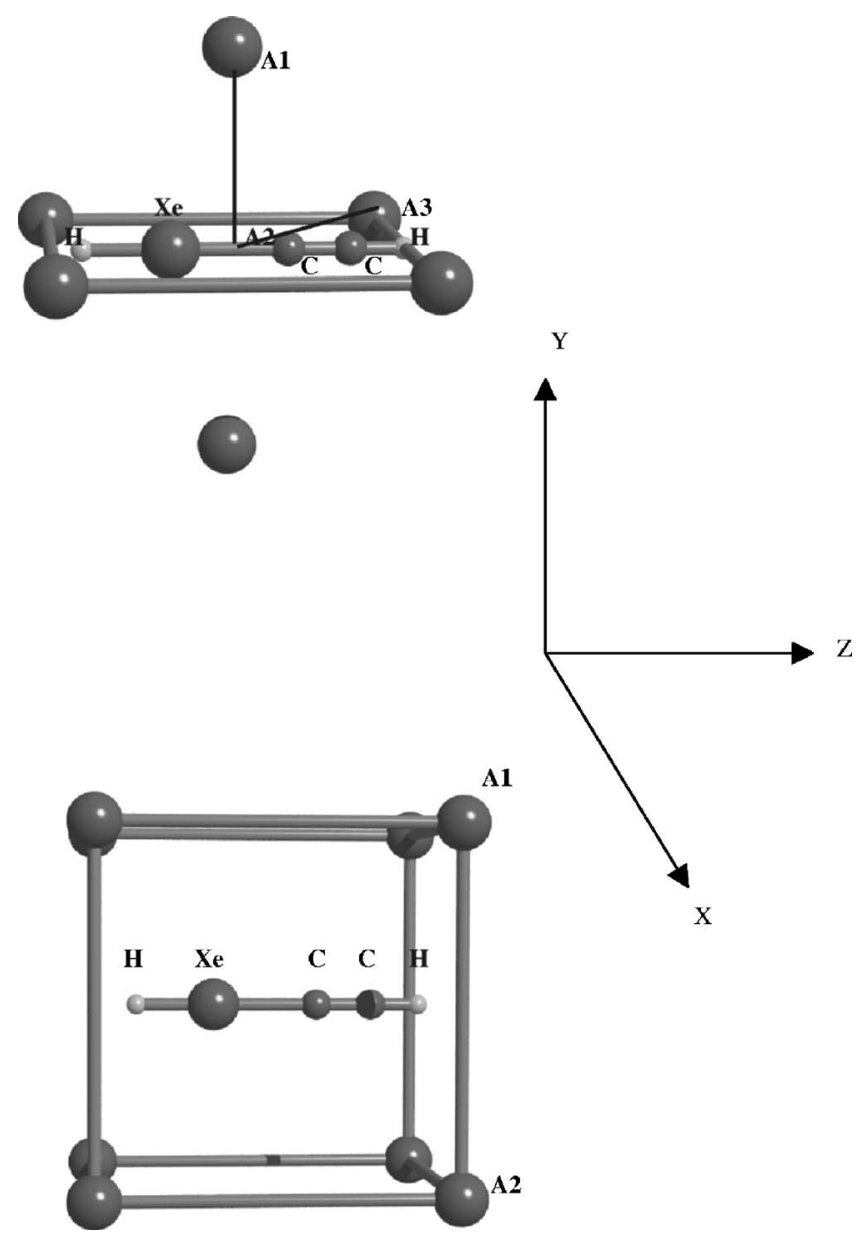

FIG. 2. Six Xe atoms octahedrally placed and eight Xe atoms cubically arranged around a $\mathrm{HXeC}_{2} \mathrm{H}$ molecule. at the MP2/aug-cc-pVDZ (=B1) level and the obtained lengths are given in parentheses. The second model involves eight $\mathrm{Xe}$ atoms arranged in a cube (Fig. 2; $A_{1} A_{2}$ $=15.12$ a.u.). Employing NBO analysis, at the MP2/B1 level, we have found that an insignificant charge transfer takes place, that is, 0.02 and 0.002 electrons are transferred from the Xe environment to $\mathrm{HXeC}_{2} \mathrm{H}$, in the first and second models, respectively.

\section{D. $\mathrm{C}_{2} \mathrm{H}_{2}$ and $\mathrm{C}_{4} \mathrm{H}_{2}$}

There is an extensive literature on $\mathrm{C}_{2} \mathrm{H}_{2}$, for example, Medved et al. $^{39}$ employing the $\operatorname{CCSD}(\mathrm{T}) /$ aug-cc-pVTZ method found $\alpha_{z z}=30.43$ a.u. and $\gamma_{z z z z}=3285$ a.u., while Keir et al. experimentally determined $\alpha_{z z}=31.60$ a.u. at $632.8 \mathrm{~nm}^{40}$ Karamanis and Maroulis ${ }^{41}$ reported for $\alpha_{z z}$ of $\mathrm{C}_{4} \mathrm{H}_{2}$ the following property values, 88.37 (22 839), 85.42 (33 089), and 85.40 (30 274) a.u., at the HF, MP2, and $\operatorname{CCSD}(\mathrm{T})$ levels, respectively (basis set: $[5 s 3 p 3 d 1 f / 3 s 3 p 1 d])$. The corresponding $\gamma_{z z z z}$ values are given in parentheses. It is observed that our values, given in Table IV, are in satisfactory agreement with the above property values. Other (hyper)polarizabilty values are given in Refs. 42-48.

\section{E. Literature values for $\alpha$ and $\gamma$ of Xe}

Hohm and Trümper, ${ }^{49}$ employing refractivity data determined $\alpha=27.12$ a.u. Several high quality results have been reported for the polarizability of Xe. ${ }^{50,51}$ Shelton $^{52}$ employing electric field induced second harmonic generation reported $\gamma=6888$ a.u. Several theoretical estimates for $\gamma$ of Xe have been published. ${ }^{50,51,53}$ From the results of $\gamma$ for Xe (Table IV), it is observed that MP2 recovers most of the correlation contribution, which can be computed at the $\operatorname{CCSD}(\mathrm{T})$ level. The quality of the basis set has a very significant effect, considering the great improvement, which is achieved by using aug-cc-pV5Z, in comparison with the augcc-pVDZ result. 
TABLE IV. The dipole moment and the (hyper)polarizabilites of $\mathrm{HC} \equiv \mathrm{CH}, \mathrm{HC} \equiv \mathrm{C}-\mathrm{C} \equiv \mathrm{C}-\mathrm{H}$ and $\mathrm{Xe}$. All values are in a.u.

\begin{tabular}{lcccc}
\hline \hline Derivative & Cor. $^{\text {a }}$ & $\alpha_{z z}$ & $\mathrm{Y}_{z z z z}$ & Method \\
\hline $\mathrm{H}-\mathrm{C} \equiv \mathrm{C}-\mathrm{H}^{\mathrm{b}}$ & & 32.87 & 2664 & $\mathrm{HF} / \mathrm{B} 1^{\mathrm{c}}$ \\
& 4 & 31.64 & 3277 & $\mathrm{MP} / \mathrm{B} 1$ \\
& 4 & 31.84 & 3330 & $\mathrm{CCSD}(\mathrm{T}) / \mathrm{B} 1$ \\
$\mathrm{H}-\mathrm{C} \equiv \mathrm{C}-\mathrm{C} \equiv \mathrm{C}-\mathrm{H}^{\mathrm{d}}$ & & 86.42 & 22488 & $\mathrm{HF} / \mathrm{B} 1$ \\
& 4 & 83.66 & 31224 & $\mathrm{MP} 2 / \mathrm{B} 1$ \\
$\mathrm{Xe}$ & & 25.07 & 1973 & $\mathrm{HF} / \mathrm{B} 1$ \\
& 26 & 25.29 & 2320 & $\mathrm{MP} 2 / \mathrm{B} 1$ \\
& 26 & 27.04 & 5789 & $\mathrm{MP} 2 / \mathrm{B} 4$ \\
& 26 & 25.53 & 2388 & $\mathrm{CCSD}(\mathrm{T}) / \mathrm{B} 1$ \\
& $27.16^{\mathrm{e}}$ & $6888^{\mathrm{f}}$ & \\
& $27.08^{\mathrm{g}}$ & & \\
\hline
\end{tabular}

\footnotetext{
${ }^{\mathrm{a}}$ Total number of correlated electrons.

${ }^{\mathrm{b}}$ The geometry of the derivatives has been optimized by employing the MP2/aug-cc-pvDZ method. For Xe a small core (core: 28 electrons) has been employed (footnote b, Table I). The technique used for the computation of the properties is given in the table. A finite perturbation approach has been employed for the computation of the properties $(F=0.0, \pm 0.001, \pm 0.002$ a.u. $)$.

${ }^{\mathrm{c}} \mathrm{B} 1$ :aug-cc-pVDZ.

${ }^{\mathrm{d}}$ The geometry of Ref. 39 has been used for the computation of the properties. A numerical fitting approach has been used employing the following fields: $0.0 \pm 0.001, \pm 0.002, \pm 0.005, \pm 0.01$ a.u.

${ }^{\mathrm{e}}$ Experimental value [Ref. 51(b)].

${ }^{\mathrm{f}}$ Experimental value [Ref. 52].

${ }^{\mathrm{g}}$ Experimental value [Ref. 51(c)]

${ }^{\mathrm{h}}$ Experimental value [Ref. 51(d)].
}

\section{F. The L\&NLO properties}

The results of Table $\mathrm{V}$ mainly demonstrate how the L\&NLO properties of $\mathrm{HC}_{2} \mathrm{H}$ and $\mathrm{HC}_{4} \mathrm{H}$ are affected by inserting one or more $\mathrm{Xe}$ atoms and by extending the chain $\left(\mathrm{C}_{n}\right)$ length. The present analysis will focus on the properties along the $z$ axis, along which the molecule is placed. The other components are much smaller. For example, at the HF/ HyPol level we have found for $\mathrm{HXeC}_{2} \mathrm{H}: \alpha_{x x}=\alpha_{y y}$ $=42.98$ a.u. and $\alpha_{z z}=123.72$ a.u.; $\beta_{z x x}=\beta_{z y y}=-49.3$ a.u. and $\beta_{z z z}=1009.3$ a.u.; $\gamma_{x x x x}=\gamma_{y y y y}=13039$ a.u., $\gamma_{x x z z}=6703$ a.u. and $\gamma_{z z z z}=46661$ a.u.

The basis set effect. We have employed the basis sets aug-cc-pVnZ, where $n=2-4$ at the HF level. The effect of the basis on $\mu_{z}$ and $\alpha_{z z}$ is very small. The effect on $\beta_{z z z}$ and $\gamma_{z z z z}$, as one would expect, is larger. For example, the difference of $\gamma_{z z z z}$, employing DZ and QZ sets, is $11.7 \%$ (Table V). $\mathrm{HyPol}$ is also giving results in reasonable agreement with the properties produced with the augmented correlationconsistent basis sets.

Complete basis set limit. In Table V we present the property values at the "complete" basis set (CBS) limit. Data derived with the basis sets aug-cc-pVnZ, where $n=2-5$, have been employed at the HF and the MP2 levels. For the extrapolation to the CBS limit we have employed the function $^{54}$

$$
A(X)=A(\infty)+\mathrm{Be}^{-C(X-2)},
$$

where $A(X)$ is the property of interest, $A(\infty)$ is the property value at the CBS limit, and $X$ is the cardinal number of each set. It is observed (Table V) that as $X$ increases the properties smoothly converge, in particular, at the MP2 level, to the CBS limit. Woon and Dunning ${ }^{16}$ noted that reliable estimates of the CBS limit for molecular polarizabilities can be obtained with the augmented basis sets.

It would be useful to compare the aug-cc-pVDZ(=B1) results with the corresponding estimated CBS limits, since B1 will be used for the computation of the properties of the larger molecules. There is satisfactory agreement between the B1 data and the estimates of the CBS limit for $\mu_{z}$ and $\alpha_{z z}$ and a reasonable agreement for $\beta_{z z z}$ and $\gamma_{z z z z}$. The discrepancy observed for $\gamma_{z z z z}$ between the two approaches is likely to be due to the less satisfactory description of $\gamma$ for Xe with B1 (Tables IV).

Effect of core electrons of Xe. We have considered two cases; in the first case 18 electrons and in the second case 26 electrons have been treated explicitly and correlated for Xe. It is observed that both cases give practically the same $\mu_{z}$, $\alpha_{z z}, \beta_{z z z}$, and $\gamma_{z z z z}$ [theory: MP2/B1 and $\left.\operatorname{CCSD}(\mathrm{T}) / \mathrm{B} 1\right]$.

The relativistic effect. The employed $\mathrm{PP}$ for Xe takes into account the effect of the relativistic correction, since the PP has been adjusted by employing reference atomic valence energies computed from all electron four-component multiconfiguration Dirac-Hartree-Fock calculations for a multitude of valence and outer-core excited states. ${ }^{18}$ However, it would be useful and interesting to find out the magnitude of the relativistic effect on the considered L\&NLO properties. Thus, the relativistic correction has been estimated by comparing the HF/B4 and HF/B4/DK results (Table V). The latter data have been computed by employing for Xe a basis set (HyPol), specifically derived for relativistic computa- 
TABLE V. The dipole moment and the (hyper)polarizabilites of some Xe derivatives. All values are in a.u.

\begin{tabular}{|c|c|c|c|c|c|c|}
\hline Derivative & $a / b^{\mathrm{a}}$ & $\mu_{z}$ & $\alpha_{z z}$ & $\beta_{z z z}$ & $\gamma_{z z z z}$ & Method \\
\hline \multirow[t]{19}{*}{$\mathrm{H}-\mathrm{Xe}-\mathrm{C} \equiv \mathrm{C}-\mathrm{H}^{\mathrm{b}, \mathrm{c}}$} & & -1.430 & 123.52 & 995.5 & 42294 & $\mathrm{HF} / \mathrm{B} 1^{\mathrm{d}}$ \\
\hline & & -1.966 & 119.47 & 832.1 & 36432 & $\mathrm{HF} / \mathrm{B} 1^{\mathrm{e}}$ \\
\hline & & -1.427 & 123.87 & 1048.2 & 46780 & $\mathrm{HF} / \mathrm{B} 2^{\mathrm{f}}$ \\
\hline & & -1.423 & 123.90 & 1056.3 & 47900 & $\mathrm{HF} / \mathrm{B}^{\mathrm{g}}$ \\
\hline & & -1.422 & 123.88 & 1072.8 & 49200 & $\mathrm{HF} / \mathrm{B} 4^{\mathrm{h}}$ \\
\hline & & -1.422 & 123.89 & 1072.3 & 49300 & $\mathrm{HF}^{\mathrm{i}}$ \\
\hline & & -1.396 & 123.72 & 1009.3 & 46660 & $\mathrm{HF} / \mathrm{B} 5^{\mathrm{j}}$ \\
\hline & & -1.440 & 124.06 & 1066.4 & 48260 & $\mathrm{HF} / \mathrm{DK} / \mathrm{B} 5^{\mathrm{k}}$ \\
\hline & $4 / 26$ & -1.083 & 125.64 & 778.9 & 41262 & MP2/B1 \\
\hline & $4 / 18$ & -1.085 & 125.69 & 781.9 & 41318 & MP2/B1 \\
\hline & $4 / 26$ & -1.630 & 122.54 & 621.7 & 36024 & $\mathrm{MP} 2 / \mathrm{B} 1^{\mathrm{e}}$ \\
\hline & $4 / 16$ & -1.082 & 125,52 & 774.5 & 41046 & MP2/B1 \\
\hline & $4 / 26$ & -1.098 & 126.19 & 862.7 & 45700 & $\mathrm{MP} 2 / \mathrm{B} 2$ \\
\hline & $4 / 26$ & -1.105 & 126.45 & 890.2 & 47670 & MP2/B3 \\
\hline & $4 / 26$ & -1.111 & 126.54 & 918.4 & 49650 & MP2/B4 \\
\hline & $4 / 26$ & -1.117 & 126.63 & 925.6 & 50387 & $M P 2^{\mathrm{i}}$ \\
\hline & $4 / 26$ & -1.077 & 125.38 & 679.4 & 38740 & $\operatorname{CCSD}(\mathrm{T}) / \mathrm{B} 1$ \\
\hline & $4 / 18$ & -1.078 & 125.44 & 679.7 & 38649 & $\operatorname{CCSD}(\mathrm{T}) / \mathrm{B} 1$ \\
\hline & $4 / 16$ & -1.077 & 125.31 & 677.6 & 38709 & $\operatorname{CCSD}(\mathrm{T}) / \mathrm{B} 1$ \\
\hline \multirow[t]{2}{*}{$\mathrm{H}-\mathrm{Xe}-\mathrm{C} \equiv \mathrm{C}-\mathrm{Xe}-\mathrm{H}^{\mathrm{b}, \mathrm{l}}$} & & 0.0 & 281.60 & 0.0 & 222000 & $\mathrm{HF} / \mathrm{B} 1$ \\
\hline & $4 / 26$ & 0.0 & 289.30 & 0.0 & 378000 & $\mathrm{MP} 2 / \mathrm{B} 1$ \\
\hline \multirow[t]{2}{*}{$\mathrm{H}-\mathrm{Xe}-\mathrm{C} \equiv \mathrm{C}-\mathrm{C} \equiv \mathrm{C}-\mathrm{H}^{\mathrm{m}, \mathrm{l}}$} & & -1.745 & 198.86 & 1272.5 & 93500 & $\mathrm{HF} / \mathrm{B} 1$ \\
\hline & $4 / 26$ & -1.315 & 200.54 & 983.4 & 111190 & MP2/B1 \\
\hline \multirow[t]{2}{*}{$\mathrm{H}-\mathrm{C} \equiv \mathrm{C}-\mathrm{Xe}-\mathrm{C} \equiv \mathrm{C}-\mathrm{H}^{\mathrm{n}, \mathrm{I}}$} & & 0.0 & 171.97 & 0.0 & 2544 & $\mathrm{HF} / \mathrm{B} 1$ \\
\hline & $4 / 26$ & 0.0 & 162.00 & 0.0 & 28488 & MP2/B1 \\
\hline $\mathrm{H}-\mathrm{Xe}-\mathrm{C} \equiv \mathrm{C}-\mathrm{Xe}-\mathrm{C} \equiv \mathrm{C}-\mathrm{Xe}-\mathrm{H}^{\mathrm{o}, \mathrm{I}}$ & & 0.003 & 471.6 & 3.9 & 321600 & HF/B1 \\
\hline
\end{tabular}

\footnotetext{
${ }^{\mathrm{a}}$ Total number of correlated electrons for $\mathrm{C}$ (a) and $\mathrm{Xe}(\mathrm{b})$.

${ }^{\mathrm{b}}$ The geometry of the derivatives has been optimized by employing the MP2/aug-cc-pvDZ method. For Xe a small core (core: 28 electrons) has been employed (Ref. 18). The technique used for the computation of the properties is given in the table.

${ }^{\mathrm{c}} \mathrm{A}$ finite perturbation approach has been employed for the computation of the properties $(F=0.0, \pm 0.001$, \pm 0.002 a.u.), except of the case described by footnote $h$.

${ }^{\mathrm{d}} \mathrm{B} 1$ :aug-cc-pVDZ (footnote b, Table I).

${ }^{\mathrm{e}}$ Effective properties. Local field: $-4.4 \times 10^{-3}$ a.u.

${ }^{\mathrm{f}} \mathrm{B} 2$ :aug-cc-pVTZ (footnote b, Table I).

${ }^{\mathrm{g}} \mathrm{B} 3$ :aug-cc-pVQZ (footnote b, Table I).

${ }^{h}$ B4:aug-cc-pV5Z (footnote b, Table I). A numerical fitting approach of the following fields has been used: $0.0 \pm 0.001, \pm 0.002, \pm 0.005, \pm 0.01$ a.u.

${ }^{\mathrm{i}}$ Estimated basis set limit by employing Eq. (4).

${ }^{\mathrm{j}} \mathrm{B} 5: \mathrm{HyPol}$ (Ref. 17).

${ }^{\mathrm{k}}$ DK denotes the Douglas-Kroll approximation employed for taking into account the relativistic correction (Ref. 22).

${ }^{1}$ A numerical fitting approach has been used, employing the following fields. $0.0 \pm 0.001, \pm 0.002, \pm 0.003$, $\pm 0.004, \pm 0.005, \pm 0.008, \pm 0.01$ a.u.

${ }^{\mathrm{m}}$ The geometry of Ref. 13 was used for the computation of the properties.

${ }^{\mathrm{n}}$ The geometry of Ref. 57 was used for the computation of the properties.

${ }^{\circ}$ The geometry of the compound has been optimized by employing the HF/aug-cc-pVDZ method.
}

tions. The relativistic correction has been taken into account by using the Douglas-Kroll (DK) approximation. ${ }^{22}$ It is observed that the relativistic effects are $5.4 \%$ and $3.3 \%$, for $\beta_{z z z}$ and $\gamma_{z z z z}$, respectively, while for $\mu_{z}$ and $\alpha_{z z}$ are $3.1 \%$ and $0.3 \%$, respectively.

The correlation effect. Correlation at the MP2 level has the following effects:

(i) It increases $\alpha_{z z}$ of $\mathrm{HXeC}_{2} \mathrm{H}, \mathrm{HXeC}_{2} \mathrm{XeH}$, and $\mathrm{HXeC}_{4} \mathrm{H}$.

(ii) It decreases $\alpha_{z z}$ of $\mathrm{HC}_{2} \mathrm{XeC}_{2} \mathrm{H}$. (iii) It decreases $\mu_{z}$ (in absolute value) and $\beta_{z z z}$ of $\mathrm{HXeC}_{2} \mathrm{H}$ and $\mathrm{HXeC}_{4} \mathrm{H}$.

(iv) It leads to a small decrease of $\gamma_{z z z z}$ of $\mathrm{HXeC}_{2} \mathrm{H}$.

The CCSD(T) method decreases $\mu_{z}$ (in absolute value), $\alpha_{z z}$, $\beta_{z z z}$, and $\gamma_{z z z z}$ of $\mathrm{HXeC}_{2} \mathrm{H}$ in comparison with the MP2 values.

Effect of Xe on the (hyper)polarizabilities. Comparing the results of $\mathrm{HXeC}_{2} \mathrm{H}$ with those of $\mathrm{C}_{2} \mathrm{H}_{2}$ and $\mathrm{Xe}$, we observe that at the $\mathrm{HF} / \mathrm{B} 1$ level of theory, the effect of $\mathrm{Xe}$ is very significant (Tables IV and V). For example, it is found 
that $\quad \alpha_{z z}\left(\mathrm{HXeC}_{2} \mathrm{H}\right)-\alpha_{z z}\left(\mathrm{C}_{2} \mathrm{H}_{2}\right)-\alpha(\mathrm{Xe})=65.58$ a.u. $\quad$ This value is $113.2 \%$ of $\alpha_{z z}\left(\mathrm{C}_{2} \mathrm{H}_{2}\right)$ and $\alpha(\mathrm{Xe})$. The same trend is shown at the MP2 and $\operatorname{CCSD}(\mathrm{T})$ levels.

Due to symmetry the $\beta_{z z z}$ value of $\mathrm{C}_{2} \mathrm{H}_{2}, \mathrm{C}_{4} \mathrm{H}_{2}$, and Xe is zero. The value of $\beta_{z z z}$ for $\mathrm{HXeC}_{2} \mathrm{H}$ is very large. This may be appreciated by comparing the first hyperpolarizability of the Xe derivative with para-nitroaniline, which is 797.5 (Ref. 38) at the HF/Pol level. ${ }^{55,56}$ The effect of Xe on the formation of $\gamma_{z z z z}$ is very large. This may be seen by noting that $\gamma_{z z z z}\left(\mathrm{HXeC}_{2} \mathrm{H}\right)-\gamma_{z z z z}\left(\mathrm{C}_{2} \mathrm{H}_{2}\right)-\gamma(\mathrm{Xe})$ $=37657$ a.u. $(\mathrm{HF} / B 1) . \gamma_{z z z z}\left(\mathrm{HXeC}_{2} \mathrm{H}\right)$ is 8.1 times larger than that of $\gamma_{z z z z}\left(\mathrm{C}_{2} \mathrm{H}_{2}\right)$ and $\gamma(\mathrm{Xe})$. This effect is confirmed at the MP2 and $\operatorname{CCSD}(\mathrm{T})$ levels of theory (Table V).

Insertion of a second $\mathrm{Xe}$ atom leads to a significant increase of the (hyper)polarizability, for example, the ratio $P\left(\mathrm{HXeC}_{2} \mathrm{XeH}\right) / P\left(\mathrm{HXeC}_{2} \mathrm{H}\right)$ takes the values of 2.3 and 5.2 for $P=\alpha_{z z}$ and $P=\gamma_{z z z z}$, respectively (HF/B1). $\alpha_{z z}$ and $\gamma_{z z z z}$ of $\mathrm{HXeC}_{2} \mathrm{XeC}_{2} \mathrm{XeH}$ are considerably larger than those of $\mathrm{HXeC}_{2} \mathrm{H}$ and $\mathrm{HXeC}_{2} \mathrm{XeH}$. For example, $\quad \gamma_{z z z z}\left(\mathrm{HXeC}_{2} \mathrm{XeC}_{2} \mathrm{XeH}\right)=1.2\left[\gamma_{z z z z}\left(\mathrm{HXeC}_{2} \mathrm{H}\right)\right.$ $\left.+\gamma_{z z z z}\left(\mathrm{HXeC}_{2} \mathrm{XeH}\right)\right]$ (method:HF/B1). The significant effect of inserting one, and even more of three, $\mathrm{Xe}$ atoms on $\gamma_{z z z z}$, is shown by observing the ratios $(\mathrm{HF} / \mathrm{B} 1): \quad \gamma_{z z z z}\left(\mathrm{HXeC}_{4} \mathrm{H}\right) / \gamma_{z z z z}\left(\mathrm{HC}_{4} \mathrm{H}\right)=4.9 \quad$ and $\gamma_{z z z z}\left(\mathrm{HXeC}_{2} \mathrm{XeC}_{2} \mathrm{XeH}\right) / \gamma_{z z z z}\left(\mathrm{HC}_{4} \mathrm{H}\right)=14.3$. The results of $\mathrm{HXeC}_{4} \mathrm{H}$ and $\mathrm{HC}_{2} \mathrm{XeC}_{2} \mathrm{H}$ show that the position of $\mathrm{Xe}$ has a great effect on both $\alpha_{z z}$ and $\gamma_{z z z z}$ (Table V). For example, $\gamma_{z z z z}$ of $\mathrm{HXeC}_{4} \mathrm{H}$ is 3.9 times larger than that of $\mathrm{HC}_{2} \mathrm{XeC}_{2} \mathrm{H}$ (MP2/B1).

Vibratonal contributions. The pv contributions $\alpha_{z z}^{\mathrm{pv}}$ and $\beta_{z z z}^{\text {pv }}$ have also been computed by employing the methods HF/aug-cc-pVDZ and MP2/aug-cc-pVDZ at the double harmonic approximation level. This approximation allows us to identify the modes with more significant contribution to the properties of interest. $\alpha_{z z}^{\mathrm{pv}}\left(=\left[\mu^{2}\right]^{(0,0)}\right)$ are 96.21 and 60.13 a.u. at the HF and MP2 levels of theory, respectively. The electronic contributions computed by employing the optimized geometry at the corresponding level of theory are 115.81 (HF) and 125.98 (MP2) a.u.

Employing Eqs. (1) and (2) we can comment on the modes with the dominant contributions to $\alpha_{z z}^{\mathrm{pv}}$. It is thus found that the vibrational modes $\mathrm{H}-\mathrm{Xe}$ and $\mathrm{Xe}-\mathrm{C}$ with frequencies $1681(2021) \mathrm{cm}^{-1}$ and $313(277) \mathrm{cm}^{-1}$ at the MP2 level contribute 13.1 (7.6) and $46.8(88.5)$ to $\left[\mu^{2}\right]^{(0,0)}$. The corresponding values computed at the HF level are given in parentheses. It is inferred that the MP2 value of $\left[\mu^{2}\right]^{(0,0)}$ is remarkably smaller than the corresponding value at the HF level.

Similar observations have been made for $\beta_{z z z}^{\text {pv }}\left(=[\mu \alpha]^{(0,0)}\right)$, for which the values 431 and -835 a.u. have been computed at the HF and MP2 levels, respectively. The corresponding values for the electronic contribution to $\beta_{z z z}$ are 1040.6 and 785.6 a.u. The difference in sign between the HF and MP2 values for $[\mu \alpha]^{(0,0)}$ is noted. At the MP2 level the $\mathrm{H}-\mathrm{Xe}$ and $\mathrm{Xe}-\mathrm{C}$ modes are associated with 1212 $(1074)$ and $-2079(-669)$ a.u. contributions to $[\mu \alpha]^{(0,0)}$. The values computed at the HF level are given in parentheses. The significant effect of correlation at the MP2 level on the contribution of the $\mathrm{Xe}-\mathrm{C}$ mode is noted.

\section{G. Stability}

Tanskanen et al. ${ }^{13}$ comparing the properties of $\mathrm{HXeC}_{2} \mathrm{H}$ and $\mathrm{HXeC}_{4} \mathrm{H}$ noted that the latter is more strongly bound (by $1.06 \mathrm{eV}$ ). Evidence for this is provided by the blueshift of the $\mathrm{H}-\mathrm{Xe}$ stretching frequency for $\mathrm{HXeC}_{4} \mathrm{H}$, which has been estimated to be $23 \mathrm{~cm}^{-1}$. The shortening of $\mathrm{H}-\mathrm{Xe}$ in $\mathrm{HXeC}_{4} \mathrm{H}$ (by $0.01 \AA$ ) also indicates a greater stability. Brown et $a l .{ }^{35}$ predicted that the linear polymer made of $-\left(\mathrm{XeC}_{2}\right)-$ is characterized by high stability due to the significant energy barrier for the removal of Xe atom. Analysis of the decomposition channels shows that $\mathrm{HXeC}_{2} \mathrm{H}$ is $34 \mathrm{kcal} \mathrm{mol}^{-1}$ more stable than $\mathrm{H}+\mathrm{Xe}+\mathrm{C}_{2} \mathrm{H}$, but $104 \mathrm{kcal} \mathrm{mol}^{-1}$ less stable than $\mathrm{Xe}+\mathrm{HC}_{2} \mathrm{H} .{ }^{57}$

\section{H. Local field effect}

The discrete LF approximation has been applied in order to find the effect of the environment, which consists of the surrounding $\mathrm{Xe}$ atoms, on the computed (hyper)polarizabilities, of $\mathrm{HXeC}_{2} \mathrm{H}$. Only the dipole and induced dipole interactions between $\mathrm{HXeC}_{2} \mathrm{H}$ and the Xe environment were considered. The dipole moment and dipole polarizability of the isolated $\mathrm{HXeC}_{2} \mathrm{H}$ have been computed at the $\operatorname{CCSD}(\mathrm{T})$ level of theory with the aug-cc-pvDZ basis set (Table V), while for $\mathrm{Xe}$ atom the experimental polarizability 27.10 a.u. was used (Table IV). The crystal structure of $\mathrm{Xe}$ is a cubic closed packed, with cell parameters $a=b=c=6.2023 \AA$ and angles $\alpha=\beta=\gamma=90.0^{\circ}$. $^{58}$

We have developed two crystal models, A and B, in order to compute the LF due to the surrounding Xe atoms on $\mathrm{HXeC}_{2} \mathrm{H}$. Model A is cubic closed packed, with dimensions $a=b=c=24.8092 \AA$. It includes $255 \mathrm{Xe}$ atoms surrounding $\mathrm{HXeC}_{2} \mathrm{H}$ (Fig. 3). Model B is a parallelogram with dimensions $a=b=6.2023 \AA$ and $c=24.8092 \AA$. It includes $63 \mathrm{Xe}$ atoms (Fig. 4). This model (B) was created by the one dimensional expansion of the crystal structure of Xe along the dipole axis ( $z$ axis) of $\mathrm{HXeC}_{2} \mathrm{H}$. These models were designed in order to show how the number of $\mathrm{Xe}$ atoms, which surround $\mathrm{HXeC}_{2} \mathrm{H}$, affect the LF. The structure of models $\mathrm{A}$ and B is presented in Figs. 3 and 4. The values we computed for LF $\left(F_{z}\right)$ are $-4.4 \times 10^{-3}$ and $-4.0 \times 10^{-3}$ a.u., for models $\mathrm{A}$ and $\mathrm{B}$, respectively.

The $\mathrm{L} \& \mathrm{NLO}$ properties of $\mathrm{HXeC}_{2} \mathrm{H}$, in the presence of the LF (model A), have been computed by employing the $\mathrm{HF} / \mathrm{B} 1$ and MP2/B1 methods (Table V). We observe that there is a significant difference in some of the considered properties. For example, at the MP2 level the LF imposes the following changes, in comparison with the properties which correspond to the isolated molecule: $\mu_{z}(50.5 \%), \alpha_{z z}(2.5 \%)$, $\beta_{z z z}(20.2 \%)$, and $\gamma_{z z z z}(12.7 \%)$. A similar trend has been found at the HF level. It is observed that the greatest effect has been found for $\mu_{z}$ and $\beta_{z z z}$.

The effect of the local field on the stability of $\mathrm{HXeC}_{2} \mathrm{H}$. It is noted that the effect of the LF, which is exercised by the $\mathrm{Xe}$ atoms (model $\mathrm{A}$ ), surrounding $\mathrm{HXeC}_{2} \mathrm{H}$, is stabilizing, considering that the Xe environment lowers the energy of the above molecule by 0.0214 a.u. at the MP2 level. 


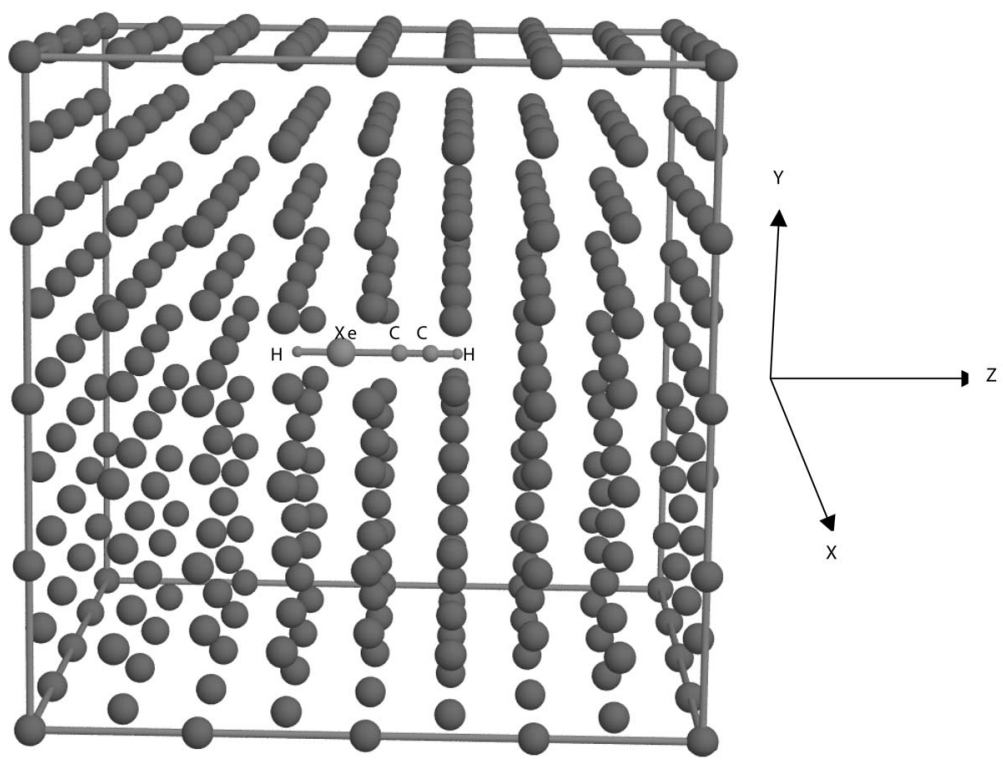

FIG. 3. $\mathrm{HXeC}_{2} \mathrm{H}$ is surrounded by $255 \mathrm{Xe}$ atoms.

\section{Interpretation of the results}

In this section we will interpret the reported L\&NLO properties. In particular, we would like to connect the changes in the electronic structure of $\mathrm{HC}_{2} \mathrm{H}$, imposed by the insertion of $\mathrm{Xe}$, with the observed change in the L\&NLO properties. This discussion relies on a sum-over-states (SOS) perturbative approach. The high-level ab initio multiconfigurational CASSCF/CASPT2 method, ${ }^{30}$ which has been successfully applied in spectroscopy and photochemistry, ${ }^{59,60}$ was employed to compute the excited states of acetylene and $\mathrm{HXeC}_{2} \mathrm{H}$, at the optimized MP2/aug-cc-pVTZ groundstate geometries. Relativistic ANO-RCC type one-electron basis sets ${ }^{61,62}$ contracted to $\mathrm{Xe}[7 s 6 p 4 d 2 f 1 g] / \mathrm{C}[4 s 3 p 2 d 1 f] /$ $\mathrm{H}[3 s 2 p 1 d]$ were employed.

Different active spaces were tested to assure the reliability of the obtained results. The final calculations comprise 10 electrons distributed in 14 orbitals, $\operatorname{CASSCF}(10,14)$, and include $3 \sigma, 2 \pi, 3 \sigma^{*}$, and $2 \pi^{*}$ valence orbitals plus four Rydberg orbitals, one $s$ and three $p$. The standard zeroth-order CASPT2 Hamiltonian was employed, whereas an imaginary level shift of 0.2 a.u. was used in order to avoid intruder state problems. ${ }^{63}$ Transition dipole moments (TDMs) are then obtained at the CASSCF level, whereas excitation energies are computed at the CASPT2 level. The calculations were performed with the quantum chemistry package MOLCAS.6.0. ${ }^{33}$

Table VI compiles computed excitation energies and os- cillator strengths for $\mathrm{HC}_{2} \mathrm{H}$ and $\mathrm{HXeC}_{2} \mathrm{H}$, together with the values obtained using the SOS expressions for ground-state polarizabilities, and first and second (three-state SOS) hyperpolarizabilities. ${ }^{64-67}$ Excitation energies of acetylene are favorably compared with other values, experimental or theoretical. ${ }^{68,69}$ Focusing on the excited states structure of both molecules, two striking features can be observed.

First, insertion of the Xe atom leads to much larger $\sigma$ bonds and therefore lower energy excited states with involvement of $\sigma, \sigma^{*}$ orbitals in $\mathrm{HXeC}_{2} \mathrm{H}$, as compared to the $\mathrm{HC}_{2} \mathrm{H}$ spectrum. Unlike acetylene, where the low-lying $\pi \sigma^{*}$ state ( $\sigma$ is mainly the antibonding CC orbital) is expected above $9.0 \mathrm{eV}$, in $\mathrm{HXeCCH}$ the lowest singlet excited state (of $\pi \sigma^{*}$ type), at the ground-state geometry, is computed at $5.32 \mathrm{eV}$ and involves the $\sigma_{\mathrm{Xe}-\mathrm{H}^{*}}$ antibonding orbital, with diffuse Rydberg-like $s$ character, whereas the second singlet excited state, computed at $6.45 \mathrm{eV}$, is of $\sigma \sigma^{*}$ character. It is observed that the low-lying valence $\pi \pi^{*}$ states are not strongly perturbed by the insertion of the Xe atom, and therefore they cannot be considered responsible for the change of the NLO property values (Table VI).

The second important difference is the reduction of the symmetry in $\mathrm{HXeC}_{2} \mathrm{H}$, which yields much larger oscillator strength values for many of the transitions. As a consequence, in $\mathrm{HXeC}_{2} \mathrm{H}$, we have an electronic spectrum lower

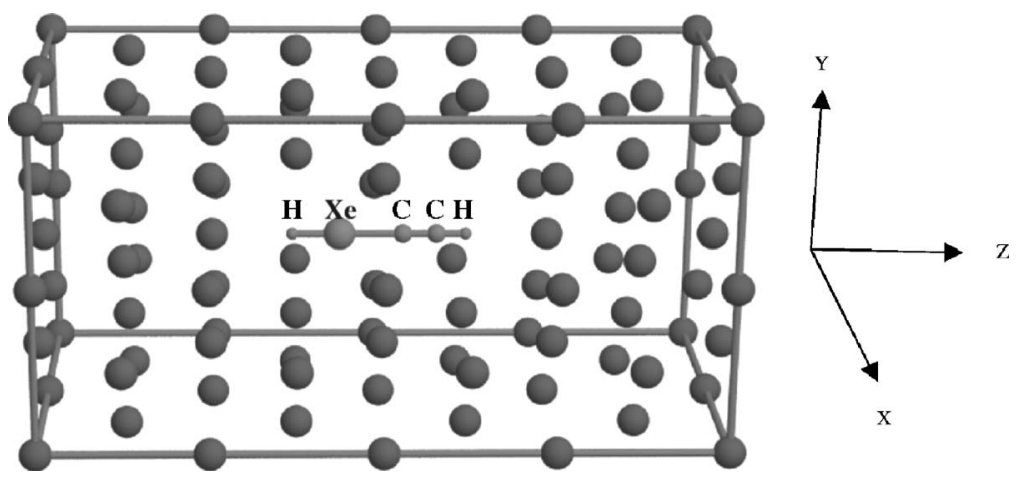

FIG. 4. $\mathrm{HXeC}_{2} \mathrm{H}$ is surrounded by $63 \mathrm{Xe}$ atoms. 
TABLE VI. Experimental and CASPT2 computed excitation energies $(\Delta E / \mathrm{eV})$ as well as related oscillator strengths $(f)$ for the low-lying excited singlet states of $\mathrm{HC}_{2} \mathrm{H}$ and $\mathrm{HXeC}_{2} \mathrm{H}$. The L\&NLO properties estimated by means of the SOS approach are also included.

\begin{tabular}{|c|c|c|c|c|c|c|}
\hline \multirow[b]{2}{*}{ State } & \multicolumn{3}{|c|}{$\mathrm{HC}_{2} \mathrm{H}$} & \multicolumn{3}{|c|}{$\mathrm{HXeC}_{2} \mathrm{H}$} \\
\hline & $\Delta E$ & $f$ & Exp. $^{a}$ & State & $\Delta E$ & $f$ \\
\hline$X^{1} \Sigma_{g}^{+}$ & $\cdots$ & $\cdots$ & $\cdots$ & $X^{1} \Sigma^{+}$ & $\cdots$ & $\cdots$ \\
\hline $1^{1} \Sigma_{u}^{8}\left(\pi \pi^{*}\right)$ & 6.67 & $\cdots$ & 7.1 & $1{ }^{1} \Pi\left(\pi \sigma^{*}\right)$ & 5.32 & 0.0015 \\
\hline $1{ }^{1} \Delta_{u}\left(\pi \pi^{*}\right)$ & 7.05 & $\ldots$ & 7.2 & $2{ }^{1} \Sigma^{+}\left(\sigma \sigma^{*}\right)$ & 6.45 & 0.3805 \\
\hline $1{ }^{1} \Pi_{u}(\pi 3 s)$ & 8.08 & 0.0933 & 8.16 & $1^{1} \Sigma^{-}\left(\pi \pi^{*}\right)$ & 6.51 & $\ldots$ \\
\hline $1{ }^{1} \Pi_{g}\left(\pi 3 p_{\sigma}\right)$ & 8.39 & $\ldots$ & 8.55 & $1{ }^{1} \Delta\left(\pi \pi^{*}\right)$ & 6.72 & $\ldots$ \\
\hline $1^{1} \Sigma_{g}^{-}\left(\pi 3 p_{\pi}\right)$ & 9.08 & $\cdots$ & $\cdots$ & $2{ }^{1} \Pi(\pi 3 s)$ & 7.00 & 0.0315 \\
\hline $1^{1} \Delta_{g}\left(\pi 3 p_{\pi}\right)$ & 9.12 & $\cdots$ & 9.02 & $3{ }^{1} \Sigma^{+}\left(\sigma \sigma^{*}\right)$ & 7.50 & 0.1932 \\
\hline $2^{1} \Sigma_{g}^{+}\left(\pi 3 p_{\pi}\right)$ & 9.13 & $\ldots$ & 9.21 & $3{ }^{1} \Pi\left(\pi 3 p_{\sigma}\right)$ & 7.53 & 0.0123 \\
\hline $2{ }^{1} \Sigma_{u}^{+}\left(\pi \pi^{*}\right)$ & 10.27 & 0.9757 & $\cdots$ & $4{ }^{1} \Pi\left(\sigma \pi^{*}\right)$ & 7.57 & 0.6146 \\
\hline \multicolumn{7}{|c|}{ SOS-computed NLO properties } \\
\hline \multirow{3}{*}{$\alpha_{z z}=11.07$ a.u. } & & & & $\mu_{z}=-0.71$ a.u. & & \\
\hline & & & & $\alpha_{z z}=26.51$ a.u. & & \\
\hline & & & & $\beta_{z z z}=557.5$ a.u. & & \\
\hline$\gamma_{z z z z}=3473$ a.u. & & & & $\gamma_{z z z z}=9102$ a.u. & & \\
\hline
\end{tabular}

${ }^{\mathrm{a}}$ For values and assignments see discussion in Refs. 68 and 71.

in energy, more dense (in the number of low-lying states), and with many nonzero contributions in the transition dipole moment matrix.

The NLO properties, according to the SOS expression, are proportional to products of TDM elements and inversely proportional to products of energy differences, and, therefore, in this case an enhancement of the NLO values of $\mathrm{HXeC}_{2} \mathrm{H}$ can be expected with respect to acetylene. Indeed, as reported in Table VI, SOS-computed $\alpha_{z z}$ and $\gamma_{z z z}$ of $\mathrm{HXeC}_{2} \mathrm{H}$ increase with respect to $\mathrm{HC}_{2} \mathrm{H}$, by two- and threefold factors. Although the proportionality is far from the near four- and tenfold factors obtained by the CCSD(T)/B1 (Table $\mathrm{V})$, it clearly reflects the expected trends. It is necessary to remember that for a better performance of the SOS method, a much larger number of excited states must be taken into account. ${ }^{67}$

\section{CONCLUDING REMARKS}

We presented the L\&NLO properties of $\mathrm{HXeC}_{2} \mathrm{H}$, $\mathrm{HXeC}_{2} \mathrm{XeH}$, and three of the Xe derivatives of $\mathrm{HC}_{4} \mathrm{H}$. We have computed the NBO charge distribution of the considered derivatives and discussed how the intramolecular environment affects the charge of $\mathrm{Xe}$ and the other involved atoms.

The weights of the five resonance structures of $\mathrm{HXeC}_{2} \mathrm{H}$ have been calculated and the bonding, which is instrumental in the understanding of the extraordinary L\&NLO properties of the derivatives of interest, has been analyzed. Since the considered organoxenon derivatives have been synthesized in a xenon matrix, we have computed the effect of the local field, which is produced by the Xe environment on the L\&NLO properties of $\mathrm{HXeC}_{2} \mathrm{H}$. By employing two models (an octahedral and a cubic one) we have found that an insignificant charge transfer takes place between the Xe environment and $\mathrm{HXeC}_{2} \mathrm{H}$. In addition, we have computed the effect of the LF on the properties of interest and it has been found that in some cases it is significant $\left(\mu_{z}, \beta_{z z}\right)$. We have performed a detailed analysis of the factors which affect the quality of the results (e.g., basis set, correlation, relativistic correction, core electrons of $\mathrm{Xe}$ ). The main result of this work is the great effect of the inserted Xe on the L\&NLO properties of the resulting derivatives. This significant result has been rationalized by employing the changes in the electronic spectrum, which are induced by the inserted Xe. The proposed interpretation scheme has been verified by SOS calculations.

\section{ACKNOWLEDGMENTS}

L.S.A. acknowledges financial support obtained by Project Nos. CTQ2004-01739 and CTQ2007-61260 of the Spanish MEC/FEDER and GV06-192 of the Generalitat Valenciana. The authors would like to thank Professor A. J. Sadlej for his useful comments.

${ }^{1}$ L. Pauling, J. Am. Chem. Soc. 55, 895 (1933).

${ }^{2}$ P. Laszlo and G. J. Schrobilgen, Angew. Chem., Int. Ed. 27, 479 (1988).

${ }^{3}$ N. Bartlett, Proc. Chem. Soc., London 1962, 218.

${ }^{4}$ K. O. Christe, Angew. Chem., Int. Ed. 40, 1419 (2001).

${ }^{5}$ R. E. Rundle, J. Am. Chem. Soc. 85, 112 (1963).

${ }^{6}$ J. Lundell, A. Cohen, and R. B. Gerber, J. Phys. Chem. A 106, 11950 (2002).

${ }^{7}$ M. Pettersson, J. Lundell, and M. Räsänen, Eur. J. Inorg. Chem. 1999, 729.

${ }^{8}$ H. J. Frohn and S. Jakobs, J. Chem. Soc., Chem. Commun. 1989, 625.

${ }^{9}$ L. Khriachtchev, H. Tanskanen, J. Lundell, M. Pettersson, H. Kiljunen, and M. Räsänen, J. Am. Chem. Soc. 125, 4696 (2003).

${ }^{10}$ M. Fankowski, A. M. Smith-Gicklhorn, and V. E. Bondybey, Can. J. Chem. 82, 837 (2004).

${ }^{11}$ V. I. Feldman, F. F. Sukhov, A. Y. Orlov, and I. V. Tyulpina, J. Am. Chem. Soc. 125, 4698 (2003).

${ }^{12}$ G. Maier and C. Lautz, Eur. J. Org. Chem. 1998, 769.

${ }^{13}$ H. Tanskanen, L. Khriachtchev, J. Lundell, H. Kiljunen, and M. Räsänen, J. Am. Chem. Soc. 125, 16361 (2003).

${ }^{14}$ T. Helgaker, P. Jørgensen, and J. Olsen, Molecular Electronic Structure Theory (Wiley, New York, 2000).

${ }^{15}$ T. H. Dunning, Jr., J. Chem. Phys. 90, 1007 (1989).

${ }^{16}$ D. E. Woon and T. H. Dunning, J. Chem. Phys. 99, 1914 (1993). 
${ }^{17}$ T. Pluta and A. J. Sadlej, Chem. Phys. Lett. 297, 391 (1988); http:// molpir.fns.uniba.sk/baslib.html

${ }^{18}$ K. A. Peterson, D. Figgen, E. Goll, H. Stoll, and M. Dolg, J. Chem. Phys. 119, 11113 (2003).

${ }^{19}$ T. R. Cundari, H. A. Kurtz, and T. Zhou, J. Phys. Chem. A 104, 4711 (2000).

${ }^{20}$ B. Jansik, B. Schimmelpfennig, P. Norman, Y. Mochizuki, Y. Luo, and H. Ågren, J. Phys. Chem. A 106, 395 (2002)

${ }^{21}$ M. G. Papadopoulos, H. Reis, A. Avramopoulos, S. Erkoç, and L. Amirouche, J. Phys. Chem. B 109, 18822 (2005).

${ }^{22}$ M. Douglas and N. M. Kroll, Ann. Phys. 82, 89 (1974); B. A. Hess, Phys. Rev. A 33, 3742 (1986); M. Barysz and A. J. Sadlej, J. Mol. Struct.: THEOCHEM 573, 181 (2001) and references therein.

${ }^{23}$ D. M. Bishop and B. Kirtman, J. Chem. Phys. 95, 2646 (1991).

${ }^{24}$ B. Kirtman and J. M. Luis, in Non-linear Optical Properties of Matter, edited by M. G. Papadopoulos, A. J. Sadlej, and J. Leszczynski (Springer, New York, 2006), p. 101.

${ }^{25}$ D. M. Bishop, Adv. Chem. Phys. 104, 1 (1998).

${ }^{26}$ D. M. Bishop and B. Kirtman, J. Chem. Phys. 108, 10013 (1998).

${ }^{27}$ A. Avramopoulos, M. G. Papadopoulos, and H. Reis, J. Phys. Chem. B 111, 2546 (2007)

${ }^{28}$ J. Li and R. McWeeny, Int. J. Quantum Chem. 89, 208 (2002); R. McWeeny, Adv. Quantum Chem. 31, 15 (1999).

${ }^{29} \mathrm{~J}$. Li, B. Duke, and R. McWeeny, vB2000, Version 1.8 (R2), SciNet Technologies, San Diego, CA, (2006); http://www.vb2000.net/

${ }^{30}$ K. Andersson, P.- $\AA$. Malmqvist, and B. O. Roos, J. Chem. Phys. 96, 1218 (1992)

${ }^{31}$ M. J. Frisch, G. W. Trucks, H. B. Schlegel, G. E. Scuseria, M. A. Robb, J. R. Cheeseman, V. G. Zakrzewski, J. A. Montgomery, Jr., R. E. Stratmann, J. C. Burant, S. Dapprich, J. M. Millam, A. D. Daniels, K. N. Kudin, M. C. Strain, O. Farkas, J. Tomasi, V. Barone, M. Cossi, R. Cammi, B. Mennucci, C. Pomelli, C. Adamo, S. Clifford, J. Ochterski, G. A. Petersson, P. Y. Ayala, Q. Cui, K. Morokuma, D. K. Malick, A. D. Rabuck, K. Raghavachari, J. B. Foresman, J. Cioslowski, J. V. Ortiz, A. G. Baboul, B. B. Stefanov, G. Liu, A. Liashenko, P. Piskorz, I. Komaromi, R. Gomperts, R. L. Martin, D. J. Fox, T. Keith, M. A. Al-Laham, C. Y. Peng, A. Nanayakkara, C. Gonzalez, M. Challacombe, P. M. W. Gill, B. Johnson, W. Chen, M. W. Wong, J. L. Andres, C. Gonzalez, M. HeadGordon, E. S. Replogle, and J. A. Pople, Gaussian 98, Revision, A.2, Gaussian, Inc., Pittsburgh PA, 1998.

${ }^{32}$ T. Helgaker, H. J. Aa. Jensen, P. Joergensen, J. Olsen, K. Ruud, H Aagren, A. A. Auer, K. L. Bak, V. Bakken, O. Christiansen, S. Coriani, P. Dahle, E. K. Dalskov, T. Enevoldsen, B. Fernandez, C. Haettig, K. Hald, A. Halkier, H. Heiberg, H. Hettema, D. Jonsson, S. Kirpekar, W. Klopper, R. Kobayashi, H. Koch, K. V. Mikkelsen, P. Norman, M. J. Packer, T. B. Pedersen, T. A. Ruden, P. Salek, A. Sanchez, T. Saue, S. P. A. Sauer, B. Schimmelpfennig, K. O. Sylvester-Hvid, P. R. Taylor, and O. Vahtras, DALTON, Release 2.0, 2005.

${ }^{33} \mathrm{~K}$. Andersson, M. Barysz, A. Bernhardsson, M. R. A. Blomberg, Y. Carissan, D. L. Cooper, M. Cossi, M. P. Fülscher, L. Gagliardi, C. de Graaf, B. Hess, G. Hagberg, G. Karlström, R. Lindh, P.-Å. Malmqvist, T. Nakajima, P. Neogrády, J. Olsèn, J. Raab, B. O. Roos, U. Ryde, B. Schimmelpfennig, M. Schütz, L. Seijo, L. Serrano-Andrés, P. E. M. Siegbahn, J. Stålring, T. Thorsteinsson, V. Veryazov, and P.-O. Widmark, MOLCAS, version 6.0, Department of Theoretical Chemistry, Chemical Centre, University of Lund, P.O.B. 124, S-221 00 Lund, Sweden, 2004.

${ }^{34}$ Dipole moment, 1 a.u. $=8.47831 \times 10^{-30} \mathrm{C} \mathrm{m}$; polarizability, 1 a.u. $=0.164867 \times 10^{-40} \mathrm{C}^{2} \mathrm{~m}^{2} \mathrm{~J}^{-1}$; first hyperpolarizability, 1 a.u. $=0.320662$ $\times 10^{-52} \mathrm{C}^{3} \mathrm{~m}^{3} \mathrm{~J}^{-2}$; second hyperpolarizability, 1 a.u. $=0.623597$ $\times 10^{-64} \mathrm{C}^{4} \mathrm{~m}^{4} \mathrm{~J}^{-3}$.

${ }^{35}$ E. Brown, A. Cohen, and R. B. Gerber, J. Chem. Phys. 122, 171101 (2005).

${ }^{36}$ (a) N. Runeberg, M. Pettersson, L. Khriachtchev, J. Lundell, and M.
Räsänen, J. Chem. Phys. 114, 836 (2001); (b) H. B. Chirgwin and C. A. Coulson, Proc. R. Soc. London, Ser. A 2, 196 (1950).

${ }^{37}$ P. C. Hiberty, R. Ramozzi, L. Song, W. Wu, and S. Shaik, Faraday Discuss. 135, 261 (2007)

${ }^{38}$ A. Avramopoulos, H. Reis, J. Li, and M. G. Papadopoulos, J. Am. Chem. Soc. 126, 6179 (2004).

${ }^{39}$ M. Medved, J. Noga, D. Jacquemin, and E. A. Perpete, Int. J. Quantum Chem. 102, 209 (2005); P. Karamanis and G. Maroulis, Chem. Phys. Lett. 376, 403 (2003).

${ }^{40}$ R. I. Keir, D. W. Lamb, G. L. D. Ritchie, and J. N. Watson, Chem. Phys. Lett. 279, 22 (1997).

${ }^{41}$ P. Karamanis and G. Maroulis, Chem. Phys. Lett. 376, 403 (2003).

${ }^{42}$ T. Zhou and C. E. Dykstra, J. Phys. Chem. A 104, 2204 (2000).

${ }^{43}$ A. Karpfen, J. Phys. Chem. A 103, 11431 (1999).

${ }^{44}$ C. J. Jameson and P. W. Fowler, J. Chem. Phys. 85, 3432 (1986).

${ }^{45}$ G. Maroulis and A. J. Thakkar, J. Chem. Phys. 95, 9060 (1991).

${ }^{46}$ A. Rizzo and N. Rahman, Laser Phys. 9, 1 (1999).

${ }^{47}$ S. Nakagawa, Chem. Phys. Lett. 246, 256 (1995).

${ }^{48}$ O. Quinet and B. Champagne, Int. J. Quantum Chem. 80, 871 (2000).

${ }^{49}$ U. Hohm and U. Trumper, Chem. Phys. 189, 443 (1994).

${ }^{50}$ G. Maroulis, A. Haskopoulos, and D. Xenides, Chem. Phys. Lett. 396, 59 (2004)

${ }^{51}$ (a) P. Soldán, E. P. F. Lee, and T. G. Wright, Phys. Chem. Chem. Phys. 3, 4661 (2001); (b) A. Kumar and M. J. Meath, Can. J. Chem. 63, 1616 (1985); (c) J. Huot and T. K. Bose, J. Chem. Phys. 95, 2683 (1991); (d) U. Hohm and K. Kerl, Mol. Phys. 69, 803 (1990).

${ }^{52}$ D. P. Shelton, Phys. Rev. A 42, 2578 (1990).

${ }^{53}$ T. Nakajima and K. Hirao, Chem. Lett. 2001, 766.

${ }^{54}$ D. E. Woon and T. H. Dunning, J. Chem. Phys. 99, 3730 (1993).

${ }^{55}$ A. J. Sadlej, Collect. Czech. Chem. Commun. 53, 1995 (1988).

${ }^{56}$ The newest release for polarized basis sets, for nonrelativistic calculations, is stored at http://molpir.fns.uniba.sk/Pol.txt

${ }^{57}$ T. Ansbacher and R. B. Gerber, Phys. Chem. Chem. Phys. 8, 4175 (2006).

${ }^{58}$ D. R. Sears and H. P. Klug, J. Chem. Phys. 37, 3002 (1962); http:// www.webelements.com/webelements/elements/text/Xe/xtal.html

${ }^{59}$ L. Serrano-Andrés and M. Merchán, in Encyclopedia of Computational Chemistry, edited by P. v. R. Schleyer, P. R. Schreiner, H. F. Schaefer III, W. L. Jorgensen, W. Thiel, and R. C. Glen (Wiley, Chichester, 2004).

${ }^{60}$ M. Merchán and L. Serrano-Andrés, in Computational Photochemistry, edited by M. Olivucci (Elsevier, Amsterdam, 2005).

${ }^{61}$ P.-O. Widmark, P.-Å. Malmqvist, and B. O. Roos, Theor. Chem. Acc. 77, 291 (1990).

${ }^{62}$ B. O. Roos, R. Lindh, P.-Å. Malmqvist, V. Veryazov, and P.-O. Widmark, J. Phys. Chem. A 108, 2851 (2005).

${ }^{63}$ N. Forsberg and P.-Å. Malmqvist, Chem. Phys. Lett. 274, 196 (1997).

${ }^{64}$ D. R. Kanis, M. A. Ratner, and T. J. Marks, J. Am. Chem. Soc. 114, 10338 (1992).

${ }^{65}$ S. A. Locknar, L. A. Peteanu, and Z. Shuai, J. Phys. Chem. A 103, 2197 (1999).

${ }^{66}$ B. M. Pierce, J. Chem. Phys. 91, 791 (1989).

${ }^{67}$ L. Serrano-Andrés, R. Pou-Amérigo, M. P. Fülscher, and A. C. Borin, J. Chem. Phys. 117, 1649 (2002).

${ }^{68}$ M. Peric, R. J. Buenker, and S. D. Peyerimhoff, Mol. Phys. 53, 1177 (1984).

${ }^{69}$ K. Malsch, R. Rebentisch, P. Swiderek, and G. Hohneicher, Theor. Chem. Acc. 100, 171 (1998).

${ }^{70}$ (a) L. A. LaJohn, P. A. Christiansen, R. B. Ross, T. Atashroo, and W. C. Ermler, J. Chem. Phys. 87, 2812 (1987); (b) W. R. Wadt and P. J. Hay, ibid. 82, 284 (1985)

${ }^{71}$ K. Malsch, R. Rebentisch, P. Swiderek, and G. Hohlneicher, Theor. Chem. Acc. 100, 171 (1998). 